\title{
VIDA ECONÓMICA Y CONTRADICCIONES SOCIOPOLÍTICAS DE UNA ELITE LOCAL EN LA FRONTERA: ENTRE EL PROTECCIONISMO ESTATAL O EL LIBRECAMBISMO EN LA CIUDAD Y EL PUERTO DE ARICA (1900-1958)*
}

\author{
ECONOMIC LIFE AND SOCIOPOLITICAL CONTRADICTIONS OF A LOCAL \\ ELITE AT THE BORDER TERRITORY: BETWEEN STATE PROTECTIONISM AND \\ FREE TRADE IN THE CITY AND PORT OF ARICA (1900-1958)
}

\author{
Daniel Ignacio Soto Tancara ${ }^{* *}$ y Diego Luis Yampara Yampara***
}

\begin{abstract}
En este artículo se analiza la relación entre el puerto y la ciudad de Arica por medio del análisis de la vida económica en la frontera norte, en el marco de su incorporación al Estado chileno, desde la perspectiva de la elite local (1900-1958). Se analizan específicamente los antecedentes de la relación entre la ciudad y el puerto de Arica, en términos socioeconómicos, durante las primeras décadas del siglo XX; y, en segundo lugar, se analizan los debates económicos y políticos de la elite local, generados en el marco de la aplicación del proyecto de Puerto Libre en la frontera norte. Mediante el análisis coyuntural de la primera mitad del siglo $\mathrm{XX}$, se concluye que los proyectos y visiones de la elite fueron contradictorios a la hora de propiciar las políticas estatales que permitieron la articulación del Puerto Libre, toda vez que debieron sortear tal demanda en un territorio con escasas condiciones para impulsar agendas económicas a nivel del Estado central.
\end{abstract}

Palabras claves: Vida económica, ciudad y puerto de Arica, elite local, Puerto Libre.

This article analyzes the relationship between the port and the city of Arica through the analysis of economic life on the northern border, within the framework of its incorporation into the Chilean State, from the perspective of the local elite (1900-1958). The antecedents of the relationship between the city and the port of Arica are specifically analyzed, in socioeconomic terms, during the first decades of the 20th century; and, secondly, it analyzes the economic and political debates of the local elite, generated within the framework of the implementation of the Free Port project on the northern border. Through the conjunctural analysis of the first half of the 20th century, it is concluded that the projects and visions of the elite were contradictory at the time of promoting the state policies that allowed the articulation of the Free Port, since they had to overcome such demand in a territory with few conditions to promote economic agendas at the central State level.

Key words: Economic life, Arica port \& Arica city, local elite, Free Port.

\section{Introducción}

La frontera norte de Chile ha sido históricamente uno de los centros neurálgicos de circulación de mercancías dentro de la región centro-sur andina en Sudamérica. Desde los siglos XVI hasta el XX, el territorio de Arica y Parinacota se constituyó como un espacio relevante para el tránsito de productos tales como la plata, el oro y otro tipo de minerales metálicos y no metálicos, provenientes de Potosí (en Bolivia), Huancavelica (en Perú), o Choquelimpie (en Chile) (Díaz, Salazar, y Soto, 2016) (Soto, 2017), así como de la lana y otros derivados provenientes de la incipiente industria ganadera altoandina, sobre todo a partir del ciclo lanero en el sur peruano (Tamayo, 1982) (Romero, 2006).

Específicamente el puerto de Arica, emplazado al sur de dicha ciudad -y sin sufrir desplazamiento espacial alguno desde tiempos coloniales (Dilla, 2016)-, ha sorteado diversas coyunturas, cambios de régimen republicano, guerras y conflictos diplomáticos, forjándose así, desde los años iniciales de la chilenización del territorio, en un espacio de frontera que, a decir de su centralidad geográfica comercial, mantuvo una marginalidad política en el ámbito de sus definiciones y proyecciones socioeconómicas (Rosenblitt, 2013). Pese a ello, y ante el implacable y atractivo paisaje serrano y

\footnotetext{
* El presente artículo se enmarca dentro del Proyecto Fondecyt N 1190133 titulado "La intermediación urbano-portuaria en un contexto transfronterizo: Arica (2008-2018)", dirigido por el investigador Dr. Haroldo Dilla.

** Universidad de Tarapacá; Universidad de Santiago de Chile. Arica, Chile. Correo electrónico: dsototancara@gmail.com

*** Programa de Magíster en Historia, Universidad de Tarapacá. Arica, Chile. Correo electrónico: dyyampara.@gmail.com
} 
altiplánico de la frontera norte de Chile, la región de Arica y Parinacota no podría ser entendida sin la centralidad de su ambiente litoral y de su puerto principal.

La relación entre la ciudad de Arica y su ciudadanía, la región transfronteriza donde esta se sitúa, y el puerto ariqueño - puerta de entrada y salida de mercancías-, constituyen un elemento relevante a la hora de estudiar la construcción de la triple frontera norte de Chile, así como las relaciones transfronterizas generadas en aquel espacio geográfico. Durante la primera mitad del siglo XX, y ya habiéndose definido la permanencia de Arica al territorio nacional chileno (mediante el Tratado de Paz de 1929 firmado entre Chile y Perú), las dinámicas entre el puerto y la ciudad fueron variando, toda vez que el Departamento de Arica (anexado a la provincia de Tarapacá) tuvo que responder a los diferentes cambios económicos y políticos experimentados tanto en Chile como en el continente (y particularmente en los países vecinos, Perú y Bolivia) (Soto, 2019).

Luego de un proceso de asimilación nacional del territorio ariqueño, marcado por momentos problemáticos $\mathrm{y}$, hasta cierto punto, violentos (Soto, 2014) (Díaz, Galdames, \& Ruz, 2010) (González, 2008), la nueva elite gobernante chilena buscó implementar mecanismos para establecer mejores condiciones en cuanto al funcionamiento y desarrollo del puerto y del Departamento en cuestión (Keller, 1946). Desde 1930 en adelante, hasta la aplicación de las políticas de Puerto Libre (1953), la ciudad y el puerto de Arica experimentaron ciertas políticas administrativas llevadas a cabo por la elite local que buscaban responder a la contingencia social y económica, las que a su vez expresaban el deseo de la ciudadanía regional respecto de su anhelo modernizador -bajo la bandera del progreso y desarrollo (Urzúa, 1972)-, que supuso la asimilación del territorio ariqueño al Estado chileno -antiguamente perteneciente a la ex Provincia de Tacna, en tiempos peruanos(Pizarro y Ríos, 2010).

A este respecto, el presente artículo busca analizar la relación entre el puerto y la ciudad de Arica, desde la perspectiva de la elite dominante local, por medio del análisis de la vida económica en la frontera norte, en el marco de la incorporación de dicho territorio al Estado chileno, durante la primera mitad del siglo XX. Mediante ello, se busca $I$ ) analizar específicamente los antecedentes de la relación entre la ciudad y el puerto de Arica, en términos socioeconómicos, durante las primeras décadas de incorporación de Arica al territorio chileno, durante y después de la chilenización, y hasta la aplicación de la Ley $\mathrm{N}^{\circ} 303$-que crea el Puerto Libre (1953)-; para luego II) analizar algunos de los diversos planteamientos forjados en los debates económicos y políticos generados en el marco de las relaciones entre la ciudad, la macrorregión andina y el puerto, por parte de la elite dominante local, al alero de la aplicación del proyecto de Puerto Libre en la frontera norte (entre 1953 y 1957).

Para dichos fines se han revisado varias fuentes documentales primarias (diarios regionales de la época -la mayor parte de estos, provenientes del Fondo de Prensa del Archivo Histórico Vicente Dagnino- ${ }^{1}$ ) y secundarias (libros, censos y boletines económicos), así como algunos estudios realizados acerca del periodo del Puerto Libre en la frontera norte chilena, a modo de cruzar estas fuentes desde el análisis de coyunturas en perspectiva histórica (Vilar, 2013) (Carmagnani, 1984). Se espera poder comprender sintéticamente y de un modo global y contextual (Kocka, 2002) (Hobsbawm, 1983) la relevancia de un periodo significativo en la construcción de Estado en el norte de Chile, es decir, el periodo correspondiente a la primera mitad del siglo XX en la frontera norte durante y postchilenización, época de la que aún quedan resabios en la actualidad y bastantes preguntas por indagar, en el marco de la historia social, política y económica de la región más septentrional de Chile.

\section{La vida económica como categoría de análisis para el estudio histórico de la frontera norte de Chile}

Antes de iniciar con la problemática señalada, es relevante poder demarcar el enfoque teórico y epistemológico con el que se busca abordar el presente objeto de investigación. En tal sentido, cuando se habla de vida económica desde la historiografía, se hace referencia principalmente a aquello que el historiador William Sewell Jr. delimitó como “...la participación humana en la producción, el intercambio y el consumo de mercancías..." (2010, pág. 147). Tanto Sewell Jr. como otros historiadores enmarcan la vida económica como una dimensión específica dentro de la historia de la humanidad, delimitada por el desarrollo del mercado y, posteriormente, del capitalismo (Braudel, 2012) ${ }^{2}$. 
En ese sentido, pensar la vida económica dentro de dichos parámetros supone tomar en consideración las diferentes dimensiones y factores que han propiciado el desarrollo del capitalismo como fenómeno histórico y como contexto estructural (Kocka, 1989), razón por la que, lejos de tratarse de una especificidad analítica anclada en sí misma, la vida económica supone necesariamente un concepto que debe interactuar con otros campos o dimensiones de la vida humana (es decir, con lo social, lo político, lo cultural, etc.) (Boldizzoni, 2013), conforme tal concepto sea útil para facilitar la comprensión de los modos de producción y de las relaciones sociales de producción existentes en un tiempo histórico dado y en una colectividad determinada (Kula, 1970) (Vilar, 2013).

A este respecto, el historiador Carlo Cipolla fue bastante claro en afirmar que, para generar un análisis metodológico en historia social y económica, “...es necesario tener en cuenta las peculiares características fisiológicas y psicológicas del hombre [y de la mujer], tanto su racionalidad como su irracionalidad, sus características mentales, sociales y culturales, todo ello a escala individual y colectiva..." (1991, pág. 15). Una visión de la vida social y económica situada bajo tales parámetros, entonces, debe aproximarse necesariamente a enfoques que permitan establecer una mirada analítica global, o por lo menos, tendiente hacia visiones multidimensionales, parámetros que en este caso pueden encontrarse en proyectos de investigación histórico-sociales como los de Eric Hobsbawm (1983), Jürgen Kocka (1989), Ellen Meiksins Wood (2018), y otros historiadores adscritos a la "historia social" o "historia de la sociedad".

Lejos de la historia segmentada en líneas fragmentadas de investigación, y lejos de enfoques que han pensado la economía como una dimensión humana separada de la cultura, la política, la ideología, etc. ${ }^{3}$, la historia social, desde la perspectiva de los historiadores antes mencionados, supone la posibilidad de comprender las diversas dimensiones de la realidad humana a escala ampliada, sin dejar de ver sus aspectos específicos, pero al mismo tiempo, sin dejar de ver los contextos globales (estructurales) en los que los seres humanos se sitúan. La historia social con enfoque económico y global, como línea de investigación, “....No [es] 'la historia de todo'...", sino que comprende, epistemológicamente hablando, “...la historia como una tela indivisible donde se interconectan todas las actividades humanas..." (Hobsbawm, 2005, pág. 6).

Lo anterior resulta relevante, ya que categorías como vida económica, si bien pueden parecer acotadas en cuanto a su campo analítico -lo económico-, necesariamente deben ser lo suficientemente sutiles como para permitir el diálogo con otras variables provenientes de la vida política (contingencia, coyunturas, correlación de fuerzas), o de la vida cultural (ideología, mentalidades, modo de vida, etc.) (Vilar, 2013). Si bien el presente artículo no pretende abarcar toda la amplia gama de factores que se interconectan dentro del contexto histórico de Arica, su puerto principal, y su elite local durante la primera mitad del siglo XX, al menos sí busca abrir paso a futuras reflexiones que reconozcan estas dimensiones -lo político, lo social, lo económico, lo ideológico, etc.- como válidas y relevantes dentro de la investigación histórica de la frontera norte, categorías que hoy vuelven a ser sugerentes en el quehacer historiográfico y científico social contingente, pese a los lastres provocados por el giro posmoderno que condenó erróneamente algunas de estas concepciones, por sus supuestas pretensiones totalizantes (Fontana y Aravena, 2011). Al fin y al cabo, como dijera Jürgen Kocka, una buena historiografía “...es, en cualquier caso, historia de las estructuras [contextos] y de las experiencias [culturales y subjetivas] al mismo tiempo. Solo a través de la conexión entre ambas se realiza plenamente..." (2002, pág. 86). El presente artículo suscribe a tales premisas.

\section{El contexto previo: la vida económica durante la chilenización de Arica a inicios del siglo XX}

Ahora bien, recalando hacia la historia de la frontera norte de Chile, desde el primer tercio del siglo XX, la región en cuestión fue objeto de políticas que buscaron remediar las limitantes económicas y sociales existentes dentro del territorio ariqueño y parinacotense. Si bien el proceso conocido por las y los historiadores como Chilenización de Tacna y Arica se cimentó sobre una retórica beligerante y xenófoba, por medio del clivaje civilización/ barbarie (donde lo segundo se asociaba al pasado peruano -indígena y afro, principalmente-, y lo primero a un presente y futuro liderado por la ocupación chilena) (González, 2008), no es menos cierto que al comenzar el nuevo siglo, la pobreza, la desigualdad social y el atraso económico dibujaron 
un escenario complejo y altamente convulsivo ${ }^{4}$ (Soto, 2017) (Basadre, 2005). Las caracterizaciones y descripciones que se realizaron del antiguo Departamento de Arica durante los primeros años del siglo pasado, en este sentido, dieron cuenta de un panorama preocupante, económicamente hablando, tanto para las nuevas elites dominantes chilenas, así como para las antiguas dirigencias peruanas. El periodista y dirigente peruano Gerardo Vargas, por ejemplo, planteaba en aquellos años que:

“...estas provincias [Tacna y Arica] son las más pobres del Perú en ese reino de la naturaleza [la minería], [y] es muy posible que en Chile se piense de distinto modo, en vista de los informes suministrados al respecto no solo por el [ex Intendente de Tacna] señor Palacios [sino] que también por otros escritores chilenos, empeñados como éste en mistificar la opinión de su país contándole cuentos de mil y una noche respecto de la importancia y riqueza de Tacna y Arica..." (1903, pág. 31 y 32).

El ambiente alicaído y penumbroso descrito por diversas fuentes de la época ${ }^{5}$, y que ya a principios de siglo propiciaba la idea de generar políticas especiales para rescatar económicamente a Arica -conforme establecer una zona libre de aranceles y atractiva para el comercio (Urzua, 1972)-, con el pasar del tiempo, fue alterándose paulatinamente, en tanto los esfuerzos realizados para mejorar las condiciones materiales del ex-Departamento y ciudad se empezaron a concretar, mediante obras de gran alcance, como la construcción del ferrocarril de Arica a La Paz ${ }^{6}$, o por medio del mejoramiento de caminos y puentes dentro de la provincia, herramientas que facilitaron la circulación de mercancías y, con ello, la mejora económica regional, una vez iniciada la nueva centuria. En 1922, por ejemplo, el agente chileno Carlos Varas planteaba aquello en los siguientes términos:

“...De aquel lugarejo [que era el Arica en tiempos peruanos] Chile ha hecho un puerto en el cual se registraron en 1919 las siguientes cifras de toneladas de embarque: 15.138 y 38.375 toneladas de desembarque. A ese puerto entraron en el mismo año 686 naves con un tonelaje de 1.025 .696 toneladas y salieron las mismas con igual tonelaje. En 1921 entraron 718 naves y salieron 718. Como movimiento marítimo esas cifras son lo bastante considerables para dar idea de un puerto importante..." (1922, pág. 96).

El mismo Varas manifestó respecto de la circulación de mercaderías que, gracias a la construcción del Ferrocarril de Arica a La Paz, se incrementaron considerablemente las proyecciones de la economía local ${ }^{7}$-generándose en 1921, con ese medio de transporte, exportaciones hacia Bolivia por el costo de $\$ 5.116,870$, mismas que por vía marina alcanzaron el valor de $\$ 1.010,051$, así como también productos bolivianos exportados por el puerto de Arica, con un valor arancelario ascendente a \$27.351,048Para el mismo año, la circulación de productos derivados de la industria minera macrorregional proporcionó altas cifras en dólares -particularmente el azufre-, todas estas tarifadas por el puerto de Arica (ver Cuadro 1).

El puerto ariqueño, en este sentido, siendo relevante para la circulación de enseres y productos derivados de la minería altoandina, reflejó la continuidad de un modo de vida económica que se había dispuesto siglos atrás en tiempos coloniales (Blanlot, 1910) (Wormald, 1972). Si bien el Departamento de Arica no se acopló enteramente a los procesos de acumulación de capital generados en Tarapacá y Antofagasta por el ciclo del nitrato -por razones que pueden entenderse a base de las tensiones gestadas por la disputa diplomática entre Chile y Perú por Tacna y Arica-, no es menos cierto que, durante el primer tercio del siglo XX, el territorio y la población local pudieron sobrellevar su marginalidad geográfica mediante el histórico tránsito comercial de enseres de la cordillera al mar y de mar a cordillera (Urzúa, 1972), lo que permitió el encuentro de experiencias entre hombres y mujeres de la frontera, por medio de la vida económica forjada en la cotidianidad de la región centro-sur andina (Flores-Galindo, 1977).

Ya para los años 1929 y 1930, y en el marco de las definiciones establecidas por el Tratado de Paz entre Chile y Perú, la circulación de mercancías por el puerto de Arica graficó el constante ir y venir de productos que tenían por destino Bolivia o Perú ${ }^{8}$, muchos de estos eran movilizados por firmas de importantes empresarios locales asociados al comercio o a las habilitaciones mineras en el departamento $^{9}$ (Soto, 2017). La vida económica, 
una vez finalizada la disputa diplomática por Tacna y Arica, siguió su tendencia secular en la frontera norte.

\section{La nueva coyuntura regional: la incertidumbre económica y el devenir de la ciudad fronteriza y del puerto ariqueño postchilenización}

Sin embargo, la década del treinta en la frontera trajo consigo ciertos problemas que debieron ser abordados por las autoridades chilenas que administraban el territorio ariqueño, ya asimilado al Estado de Chile. El crack del 29 y la depresión económica de los años siguientes trajeron consigo dificultades de suma relevancia para la macrorregión andina en términos sociales y políticos (Vitale, 2009) -por de pronto, la detonación del fin del ciclo salitrero en Chile (Palma, 1984), la convulsión social y política en Perú, producto del colapso del Estado aristocrático (Flores-Galindo, 1999), así como la convulsión social y económica que experimentara Bolivia durante la Guerra del Chaco (Pérez, 2014)-. Estos aspectos generales, a escala local, se vieron reflejados en la incertidumbre y desesperanza de la sociedad civil y elite dominante ariqueña respecto de la coyuntura por la que transitaban como ciudad y departamento (Pizarro y Ríos, 2010).

Entre 1929 y 1930 las elites chilenas locales, aun proyectándose en torno a la mejora económica y social del territorio en cuestión, plantearon la necesidad de buscar el crecimiento urbano mediante la promoción de viviendas obreras -sobre todo para los trabajadores del ferrocarril Arica a La Paz-, propuesta que posibilitaba el crecimiento demográfico de la ciudad, con lo que, a su vez, se fomentaba el control del hinterland regional fronterizo - particularmente de los valles más próximos, como Azapa y Lluta, por ejemplo- ${ }^{10}$. En paralelo, los discursos oficiales de la elite, imbuidos de una retórica modernizadora (Soto, 2017), perfilaban la necesidad de generar un proceso de sindicalización de la población regional, en tanto ello habría pasos a la necesaria formación y disciplinamiento de la fuerza de trabajo disponible en el territorio ${ }^{11}$. El gobernador del departamento de Arica, Alberto Serrano, lo dejó bastante en claro en una carta enviada a la Unión de Empleados de Chile en Arica, donde manifestaba que "...en los sindicatos [veía] el mejoramiento individual y económico..." de la ciudad por medio de "...la cooperación. Una vez formados, sus beneficios se harán sentir hondamente en la clase trabajadora..."12.

Ahora bien, pese a los discursos oficiales de la elite regional que esbozaban el salto de Arica hacia nuevos tiempos modernos, el pesar sobre el ambiente ciudadano provincial siguió estando presente, sobre todo respecto del diagnóstico económico que se tenía de Arica y su puerto, y del incierto futuro que les esperaba. La Cámara de Comercio de la ciudad, en una nota dirigida al Presidente de la República, y publicada en el diario El Ferrocarril durante el 12 de junio de 1931, manifestaba la necesidad de arbitrar “...algunas medidas para salvar la situación actual [en tanto] que Arica no tiene vida propia [y] que vive casi enteramente del tránsito de mercaderías y pasajeros de [...] Bolivia y en menor escala con las provincias del sur del Perú y que su poca vida propia consiste únicamente en la agricultura de sus pequeños valles vecinos..." (Pizarro y Ríos, 2010, pág. 80). Un año después, el editorial del mismo periódico expresó que “....era indudable que, si la internación de materias primas estuviera exenta de derechos de Aduana, se desarrollarían en Arica, industrias chilenas y manufactureras que llevarían capitales e industrias chilenas y extranjeras creando actividad comercial y atrayendo población que encontraría trabajo y vida fácil, sin el recargo que imponen estos derechos..."13.

De este modo, y ante el escenario complejo por el que atravesaban, tanto el departamento y la ciudad de Arica, así como la provincia de Tarapacá -a la que habían sido anexadas-, la idea de establecer una zona libre de aranceles e impuestos aduaneros fue creciendo entre quienes ejercían poder dentro del territorio (Urzúa, 1972). La elite regional ariqueña, a este respecto, comenzó a formar un discurso hasta cierto punto compacto, en donde reconocían las carencias del territorio, lo complejo que se hacía el gobernar una provincia tan distante del centro político de Chile -y por tanto, distante de las ventajas comparativas del centralismo-, pero al mismo tiempo, asumían lo benigno que podía ser su cercanía con territorios como Perú y Bolivia, condición geográfica que, si existieran facilidades para la circulación de mercancías, podía establecer potencialidades económicas interesantes para Arica.

$\mathrm{Al}$ finalizar la década del treinta y comenzar los años cuarenta, las exportaciones generadas entre 1937 y 1941 por el puerto de Arica arrojaron la cifra de 169 mil dólares, en tanto que las exportaciones bordearon el valor de 624 mil dólares en el mismo 
rango de años, cifra exportadora que aumentó entre 1942 y 1946 a 971 mil dólares, del mismo modo que las importaciones durante aquel rango anual fueron equivalentes a 429 mil dólares (ver Cuadro 2). Los valores monetarios por la circulación de mercancías en el puerto y zonas aduaneras dentro del territorio, dieron cuenta de ciertas mejoras dentro de la economía regional -a excepción de los saldos negativos dejados por los balances comerciales en los años 1938 (-455 mil dólares) y 1940 (-702 mil dólares), respectivamente-.

Pese a ello, las condiciones materiales de la pesca y producción marítima en Arica, a decir de su extenso litoral, siguió siendo tan precaria como la economía departamental en aquel momento. Durante los primeros meses de 1940, por ejemplo, hubo noticias de que el puerto todavía no contaba con su frigorífico -elemento proyectado desde la dirección del Instituto de Fomento Minero e Industria de Iquique-, cuestión que ocurría, a decir de lo expresado por la línea editorial del periódico La Gaceta, por:

“...1) La gruesa disminución que hizo la Corporación de Fomento de la Producción, rebajando de un millón 200 mil pesos a 600 mil, que tampoco los ha entregado.

2) La imposición que interpone la misma entidad [...] al Instituto [que] venda la instalación de Fuerza Motriz para [...] depender de quienes le vendan la Fuerza Motriz necesaria y 3) La falta de corcho" 14 .

Los problemas asociados a la fuerza motriz decían relación con la nula presencia de electricidad dentro del puerto, así como la no existencia de estructuras hidráulicas que permitieran su desenvolvimiento extractivo. Para resolver estos aspectos, las autoridades del puerto llamaron a los técnicos industriales en pesca y conserva, Epifanio Asofra y Ernesto Forrada, conforme pudieran forjar un programa de desarrollo industrial del puerto y de la producción pesquera a nivel regiona ${ }^{15}$. Sin embargo, con el pasar del tiempo, esos proyectos modernizadores parecieron estar del todo estancados. El sociólogo Carlos Keller escribió a mediados de la década del cuarenta que la actividad económica en el litoral "....apenas [era] de un estado rudimentario, tradicionalista y empírico, ofreciendo el aspecto de una pequeña industria, de tipo colonial...", situación que, en todo caso, no era distante de las condiciones existentes dentro de la misma provincia de Tarapacá, debido a que:

“...los pescadores de la provincia viven en una verdadera miseria, pues el valor medio por pescador de la producción realizada en 1941 y el primer semestre de 1942 no subió de $\$ 129,80$ mensuales, por lo cual se encuentran endeudados, sin atender debidamente sus compromisos y viven de anticipos que les hacen los intermediarios. $\mathrm{Si}$ esta es la situación en que se encuentran los pescadores, como resultado del desarrollo secular de esta industria, se comprenderá que no es fácil cambiar substancialmente las cosas..." (Keller, 1946, pág. 227)

En realidad, se podría asumir que, hasta aquel entonces, dentro del departamento y de la ciudad de Arica no se habían generado cambios tendientes a mejorar o modernizar los modos de explotación de los recursos naturales existentes, tanto en la zonas habilitadas para la pesca así como también en los pisos ecológicos habilitados para la agricultura y ganadería -zonas de valle, sierra y altiplanicie (donde además, la presencia de yacimientos mineros explotables aún estaba vigente)-, lo que da cuenta de una vida económica que aún se solventaba con bastantes atrasos productivos (Soto, 2017).

El diagnóstico realizado por Keller y otros cronistas del periodo, en general, dieron cuenta de una situación de decadencia en materia productiva, y hasta cierto punto, confirmaban que Arica no podía salir de su situación deplorable si es que no se le brindaba apoyo mediante políticas especiales de impulso económico (Galdames, 2010). La marginalidad en la que se encontraba el territorio, por otro lado, contrastaba, a decir del sentir de algunos observadores, con la situación que experimentara la vecina ciudad de Tacna en Perú, otrora urbe hermana en tiempos en que ambas conformaban una misma provincia (Basadre, 2005). Como sugirió el escritor Luis Urzúa:

“...Bien consideradas las cosas, no tenía otra solución Arica [que una política especial de Estado], ya que su falencia económica era evidente, sobre todo si se la comparaba con la vecina ciudad de Tacna. Con una edad próxima a los 400 años no había logrado superar la condición de 
aldea. Hasta 1937, año en que el Dr. Juan Noe empezó la Campaña Anti-Malárica, había podido excusar su postración con las enfermedades endémicas de sus valles; sin embargo, el total saneamiento dejó en evidencia que no era esa la única causa de su retraso, sino que necesitaba una especial protección gubernativa, por su alejamiento del centro del país e importancia política..." (1972, pág. 37).

Sumado a lo anterior, y en un contexto en el que los montos asociados a importaciones tendieron a crecer por sobre las exportaciones que registró el puerto a nivel regional -tendencia secular que se mantuvo hasta 1957 (ver Cuadro 2), y que, a decir de algunos, dio cuenta del gran desequilibrio comercial que ostentaba la economía regional de Arica en términos estructurales- (Cámara de Comercio de Santiago, 1958), el llamado a generar políticas eficaces que mejoraran las condiciones económicas de la ciudad de Arica y de su gente se hizo sentir cada vez más.

El contexto internacional de la década del cuarenta, mediado por los avatares de la Segunda Guerra Mundial, provocó que los esfuerzos por dinamizar la economía por medio del comercio internacional se hiciese cada vez más complejo (Vitale, 2009), razón por la que algunos expertos recomendaban el fomento de proyectos que impulsaran la circulación del transportes comerciales a nivel país -por ejemplo, mediante el desarrollo de compañías navieras nacionales estatales-, en tanto poder destrabar los flujos comerciales que se encontraban estancados, principalmente en las provincias del norte de Chile ${ }^{16}$. Las falencias existentes a nivel provincial y departamental en materia de inversión pública, sumadas a condiciones desiguales de gestión dentro del territorio ${ }^{17}$, confirmaban la idea de un escenario crítico para la vida económica ariqueña.

De este modo, la necesidad de hacerse cargo de la situación por la que atravesaba el sector más septentrional de la provincia de Tarapacá, de sus falencias y complejidades económicas, todas graficadas en varios estudios y reportajes mostrados en diversos periódicos regionales, ya no podía esperar más tiempo. Los actores políticos presentes en Arica, las autoridades públicas, los sectores asociados al mundo privado, entre otros, comenzaron a acercarse cada vez más a la idea de impulsar una política de zona franca para el puerto y departamento de
Arica $^{18}$, toda vez que las estrategias económicas impulsadas hacía décadas -de orientación más bien monetaristas- no dieron resultado.

\section{Los debates políticos y económicos de la elite local por el puerto libre en el departamento de Arica}

El transcurrir de las décadas en la ciudad de Arica prosiguió y, junto con él, algunas transformaciones se hicieron notar, como expresión de un cambio social de tenues características modernas (Sztompka, 1993). A nivel demográfico, por ejemplo, para la década del cincuenta ya era bastante notorio que el departamento de Arica había tenido un crecimiento poblacional considerable (distinto al decrecimiento que venía experimentando la provincia de Tarapacá a nivel global en aquel mismo periodo - presumiblemente atribuible a la crisis y decadencia de la industria salitrera-), el que, de 21 mil personas en 1930 aproximadamente, y 21.836 personas en 1940, para 1952 registró 30.307 personas habitando el territorio fronterizo, las que, en su inmensa mayoría, se concentraban en la urbe de Arica (con 23.033 personas), por sobre las subdelegaciones rurales del mismo departamento (ver Cuadro 3). La migración campo-ciudad y la concentración de población en espacios urbanizados y semiurbanizados, sujetas a las lógicas de la relación capital-trabajo, ya eran un hecho en la ciudad de Arica, así como también lo eran en Chile y en buena parte de Latinoamérica para mediados del siglo XX (Vitale, 2009). Además, si bien la situación económica del departamento y la ciudad de Arica no fue de las mejores, ya hacia finales de la década del cuarenta y a comienzos del cincuenta el comercio ariqueño mostró una tendencia secular en donde las exportaciones siguieron teniendo una relevancia preponderante por sobre las importaciones, por lo menos hasta 1953, momento en que el balance saldado entre exportaciones e importaciones tuvo un valor de 371 mil dólares -según las cifras entregadas por la Cámara de Comercio de Santiago (1958)- (ver Cuadro 2).

Sin embargo, las demandas de una política especial para Arica-que hiciera posible un cambio cualitativo respecto del mejoramiento de su matriz productiva- se hicieron sentir cada vez con más fuerza a nivel de la sociedad civil y elite dominante local. La posibilidad de establecer un puerto libre que potenciara jurídicamente la circulación de 
mercancías por el territorio era un proyecto que, como ya se ha dicho antes, apareció como idea en tiempos de la chilenización (Urzúa, 1972), pero que, con el pasar del tiempo, comenzó a tomar cada vez más fuerza a nivel del discurso público regional (Scott, 2000).

En la década del cuarenta, por ejemplo, se hicieron esfuerzos por llevar a cabo un proyecto que otorgara a la ciudad de Arica dicha condición tributaria, materia que contaba con el apoyo expreso de fuerzas políticas locales y nacionales -como el Partido Radical, por ejemplo- ${ }^{19}$, con el apoyo de diputaciones provinciales -en particular, el diputado de la provincia de Tarapacá, Humberto Arellano Figueroa- ${ }^{20}$, así como con la simpatía de diversos gremios y corporaciones de la sociedad civil regional. La posibilidad de establecer mejores condiciones para el comercio transfronterizo, mediante la liberación del pago de impuesto de productos exportados a Bolivia ${ }^{21}$, así como también la posible industrialización de áreas estratégicas de la economía regional ariqueña, sin lugar a dudas fueron vistas con buenos ojos por un sector importante de la población local ${ }^{22}$. La promesa de la modernización de Arica, mediante la aplicación de dicho proyecto de liberación tributaria en la frontera $^{23}$, se convirtieron cada vez más en una necesidad altamente demandada en el discurso público de los sectores dominantes locales. Sin embargo, las condiciones políticas para la aprobación de un proyecto de estas características no estaban dadas, según lo observado por la propia dirigencia política de la época, y por lo demás, aun existían carencias argumentativas respecto de la defensa del puerto libre como posibilidad real en Arica. Una columna enviada al diario de orientación radical, La Gaceta, así lo dejó de manifiesto:

“...a virtud [de] que la reglamentación para aplicar dicha ley tendría que forzosamente ser muy liberal, equitativa y, lo que es más, ese reglamento debería tener disposiciones de carácter extraordinario y contemplar en sus artículos, probablemente, un control especial [de] ingreso de personas jurídicas o civiles, de pasajeros disfrazados de < turistas> o comerciantes en tránsito para visitar las colosales instalaciones industriales, fabriles del emporio ariqueño resplandeciente a los ojos de propios y extraño [...] No, señor Director, Arica no puede todavía merecer los honores de puerto libre..." 24 .

De este modo, la idea de establecer un puerto libre para Arica se fue estancando con los años, a la espera de que en Santiago, desde el poder ejecutivo y el legislativo central, este planteamiento fuese tomado en serio, y no solo abordado como una promesa política de campaña en tiempos electorales ${ }^{25}$. Pasarían los años, y sería ya definitivamente en la década del cincuenta cuando tal planteamiento volvió a ser retomado, esta vez al alero de los problemas estructurales que poseía el funcionamiento del puerto en cuestión.

En 1950, la circulación de mercancías ya no solo era un problema asociado exclusivamente a la infraestructura portuaria-que en aquellos días, todavía parecía mantener características francamente deficientes (Escuela de Transporte UCV, 1972)-, sino que también, los problemas habían dejado de manifiesto que la infraestructura del Ferrocarril de Arica a La Paz se encontraba en condiciones bastante deficientes, al punto en que las autoridades ferroviarias estudiaron la posibilidad de llevar a cabo “...el arriendo de dos o tres locomotoras, ya sea al Ferrocarril de Antofagasta a Bolivia o a la propia Sec. Boliviana del F.C.A.L.P., para descongestionar en forma efectiva y rápida el transporte al altiplano...", así como también, evaluar próximamente “...la adquisición de un Grupo Eléctrico destinado exclusivamente para el funcionamiento de las grúas del muelle..."26.

La problemática del funcionamiento del puerto de Arica, esta vez vinculado también con los estragos que causaba el envejecido ferrocarril transandino, obligó a que las autoridades tomaran cartas en el asunto, y a que, por de pronto, buscaran mecanismos que establecieran un mejor y más eficiente funcionamiento del transporte ferroviario ${ }^{27}$. No obstante, los problemas no desaparecieron y cada vez se hizo más evidente que se trataba de una cuestión de tipo estructural que afectaba no solo al transporte y al puerto, sino que a todo el departamento en general. Fue en ese marco que la demanda por establecer un puerto libre que mejorara las condiciones materiales objetivas de la ciudad y departamento, mediante una jurisdicción relajada para la circulación de mercancías, volvió a resurgir por parte de la elite dominante local (Pizarro y Ríos, 2010).

A este respecto, fue en 1952, y tras el retorno del general Carlos Ibáñez del Campo a la presidencia, 
por medio del proyecto político agrario-laborista -de claras connotaciones populistas (Vitale, 2009)-, que la demanda regional por establecer un puerto libre se hizo notar con mucho ímpetu entre la población local y la elite ariqueña. No obstante, los argumentos jurídicos y políticos, si bien esta vez tuvieron una mayor capacidad técnica, no por ello dejaron de sonar un tanto contradictorios a la hora de ser expresados frente al nuevo gobierno. Y es que si antaño la demanda por un puerto libre se formuló desde una retórica que en ocasiones recalaba en un nacionalismo estatal -con argumentos patrioteros que reclamaban la presencia de una política de Estado $^{28}$-, esta vez su retórica dejaba ver la necesidad de una mayor autonomía en la gestión del departamento a nivel administrativo, e incluso más aún, validando la presencia de la industria privada por sobre la estatal como estrategia de desarrollo regional (Urzúa, 1972).

En abril de 1953, cuando el propio Carlos Ibáñez del Campo visitó Arica en el marco de su gira presidencial, dichas visiones se expresaron entre la prensa local, al alero de diferentes matices y énfasis respecto de las necesidades de la ciudad y del puerto. El director del diario La Gaceta, Damián Iglesias R., manifestó respecto de las obras portuarias en Arica que:

“...Desde hace más de una docena de años, y gastando caudales que sumados en total darían la seguridad de construir obras de verdadera utilidad, se construye nuestro bien modestísimo muelle, a lo que más de un chusco marinero le ha dado el nombre de $<<$ juguete en exhibición $>>$. Arica necesita de una obra portuaria donde puedan atracar barcos de todos los tipos y tonelajes. Es un puerto importante y por lo mismo debiera tener de parte del Gobierno, preferente atención..."29.

Y respecto del Ferrocarril de Arica a La Paz, y de los caminos al interior del departamento de Arica, manifestó el mismo director de prensa que:

“...El personal [del ferrocarril] necesita seguridades de su estabilidad, y en esa petición no impera otra cosa que justicia y por tanto no debe, por motivo alguno, ser desoída, y además está aquello que se ha venido repitiendo en innumerables ocasiones, ya que se trae desde el sur a funcionarios que solo vienen a disfrutar de mejores rentas con muy problemática mejor labor, para a corto tiempo obtener su jugosa jubilación. Eso es un vicio que debe cortarse de raíz, ya que seguir por el mismo camino es desprestigiar finalidades del actual Gobierno que merecen el más alto como firme respeto. [Por otro lado] Si [existiesen] buenos caminos, la prosperidad de esas zonas favorecidas se multiplica[ría] y donde hay mayor necesidad de esas obras viales, es precisamente, en nuestro Departamento, el cual posee en sus diferentes regiones importantes veneros metálicos que, al explotarlos, no solo harán el mayor movimiento de lo nuestro, si no que igualmente esa oportunidad da buena explotación puede llegar a otras provincias donde se necesitan de minerales para su mejor aprovechamiento industrial. Se necesita, y es urgente, darle en el presupuesto de la nación un rol preferente a las obras camineras del departamento de Arica..."30.

La argumentación del director del diario $\mathrm{La}$ Gaceta dejó entrever con claridad su punto de vista, estableciendo la necesidad de una mayor presencia del Estado en la gestión administrativa de la frontera norte. Manifestando planteamientos incluso del tipo autoritarios ${ }^{31}$, la noción de un Estado que perfilara un marco regulatorio fuerte, pero que, al mismo tiempo, garantizara la autonomía de la administración pública, parecía ir en la línea de lo que otrora tiempos chilenizadores también se señaló desde las elites dominantes chilenas en Arica ${ }^{32}$ (Pizarro y Ríos, 2010). Los representantes del gobierno de Carlos Ibáñez, sintonizando con el pensar de las autoridades de la ciudad y departamento -alcalde, gobernadores y comandantes militares-, respondieron afirmativamente a dicho clamor local de la elite ariqueña. El ministro de Hacienda en aquel entonces, Juan Bautista Rossetti, señaló que desde el gobierno agrario-laborista:
“...Queremos dar a este puerto un régimen excepcional de tratamiento, que traiga prosperidad y abundancia: tranquilidad y bienestar, $\mathrm{y}$, junto a satisfacer rápidamente las aspiraciones de que el Departamento tenga buenos caminos y en lo posible esté 
unido con la capital mediante una carretera pavimentada, que una a estas prosperas regiones nortinas con el centro del país en forma definitiva, porque Arica es no solo el primer puerto de Chile sino que debiera serlo el primero de América, por su estratégica posición internacional..."33.

Según lo señalado por el ministro Rossetti, el carácter geoestratégico del territorio ariqueño en cuestión daba cuenta de las potencialidades económicas que este tenía, no solo para Arica, sino que también para Chile ${ }^{34}$, en tanto puerta de entrada hacia el mercado sudamericano -y particularmente, hacia el mercado amazónico-. Sobre esas mismas líneas argumentales, la idea de establecer mercados protegidos, con premisas regulatorias respecto de su liberación tributaria, sintonizó bastante con aquello que en ese entonces se esgrimía como políticas desarrollistas (Larraín, 2001), las que, para el caso de Chile, se nutrieron bastante por medio de la retórica nacionalista del proyecto populista de Carlos Ibáñez (Pinto, 1970).

Sin embargo, desde una arista bastante distinta, aunque igual de favorable a la hora de evaluar la propuesta de puerto libre para Arica, se posicionó la lectura del senador por la sexta agrupación provincial "Curicó, Talca, Maule y Linares", y con importantes capitales mineros invertidos en la sierra alto ariqueña, don Eduardo Alessandri Rodríguez, perteneciente al Partido Liberal, quien en sesión de la cámara alta, y conociendo la situación de Arica respecto de su contraste con la vecina ciudad peruana de Tacna, señaló que esta última ciudad era

“...hoy en día una ciudad próspera, pujante en ininterrumpido tren de progreso, y Arica arrastra una vida lánguida y decadente. ¿Y por qué, señor presidente, ha sucedido todo esto? ¿Acaso Chile, que pobló el desierto de Atacama, y levantó puertos, ciudades y grandes industrias extractivas, donde antes que flameara su bandera solo era un inmenso despoblado terriblemente inhospitalario, ha fracasado en Arica? ..." 35 .

A lo que el mismo senador respondió enérgicamente:

“...No; de ninguna manera. Chile, como nación, no ha fracasado en Arica, como tampoco fracasó en el extremo austral del continente, en el estrecho de Magallanes y en la Tierra del Fuego, en donde el genio de la raza y el esfuerzo de la iniciativa privada de sus hijos transformó en emporios de riqueza lo que antes fueran tierras de misterio y desolación. Lo que ha arruinado principalmente a Arica, como a todo el país, es la perniciosa política de intervención estatal, que todo lo trastorna y que ahoga los mejores esfuerzos, al hacer del Estado, no un poder regulador, sino que un adversario resuelto y tenaz de la iniciativa privada. Y, precisamente, el progreso de Tacna se debe, en gran parte, al hecho de que el Gobierno de Lima, después de seguir, durante algún tiempo, la política de controles y cortapisas que tanto daño ha hecho al desarrollo de nuestro país, convencido de su inutilidad e inconveniencia, soltó las amarras que maniataban al progreso de la nación la que, libre del intervencionismo del estado y de los controles burocráticos, inició una marcha acelerada por la senda del bienestar colectivo y de la prosperidad ¡Qué contradicción entre Tacna y Arica, y que lección para los propugnadores del intervencionismo del Estado!..." ${ }^{36}$.

El diagnóstico establecido por el senador Alessandri, de este modo, y contrariamente a lo previsto por algunos discursos de la elite regional, esbozó su apoyo al proyecto de puerto libre, pero fundamentando su posición por medio de los principios del liberalismo antiestatalista, valorando el librecambismo por sobre la fijación de precios (propias del proteccionismo estatal), sobre todo en una zona geográfica como la que posee Arica, puerto natural de entrada y salida para el comercio sudamericano de la región centro-sur andina y amazónica $^{37}$ (Tamayo J. , 1959). Pidiendo al senado que "...se despache un oficio al Poder Ejecutivo solicitándole el envío de un mensaje a la Cámara de Diputados declarando al Puerto de Arica $<<$ Zona Libre Aduanera $>>$ y exento de las disposiciones de la Ley sobre Control de Cambios...", Eduardo Alessandri consideró que el país, de esta forma, “... [y] propendiendo al progreso de Arica, colocándola en igualdad de condiciones con Tacna, no solo contribuirá al bienestar y prosperidad de 
aquella, sino que también al desarrollo y progreso de toda la nación..."38.

De este modo, el 25 de abril de 1953, los anhelos de muchos ariqueños y ariqueñas -y principalmente, de la elite dominante local- se materializaron con la esperada promulgación del decreto con fuerza de ley $\mathrm{N}^{\circ} 303$, el que otorgó a Arica la categoría de puerto libre $^{39}$. Dicho reconocimiento especial, con el paso del tiempo, se hizo notar en varias transformaciones relevantes a nivel estructural, las que tuvieron un fuerte impacto en la vida económica de Arica. Por de pronto, y “...Con velocidad increíble, Arica se [llenó] de comerciantes y mercaderías importadas, a base de trasparencia nylon, conservas finas y bagatelas de bazar..." (Urzúa, 1972, pág. 38). A su vez, la demografía del departamento se alteró radicalmente, pasando de 30.307 habitantes en 1952 a 51.947 personas en 1960 , de estos, la gran mayoría se concentraron en la ciudad de Arica - estableciendo una composición demográfica de 23.033 habitantes en 1952, la que aumentó a 46.686 personas en la década de 1960-, según las cifras censales de aquellos años (ver Cuadro 3).

Sin embargo, la balanza comercial de importaciones y exportaciones, que hacía años había mantenido una tendencia secular -con preponderancia en las exportaciones-, posterior a 1953 se desajustó de manera bastante abrupta, en tanto que esas cifras, según lo recogido por la Cámara de Comercio de Santiago (1958), llevaron a balances negativos comerciales entre 1954 y 1956 (ver Cuadro 2). Estas evidencias fueron las que tomó la misma Cámara de Santiago para criticar las políticas especiales instauradas en Arica, y particularmente, criticar la idea de instaurar nuevamente un régimen especial de zona franca, con recepción tributaria a nivel local, mediante la instalación de una Junta de Adelanto de Arica ${ }^{40}$ (Ruz, Galdames, y Díaz, 2015). Los economistas y ejecutivos que agrupaba a dicho gremio mercantil capitalino, fueron enfáticos en señalar, en un informe contrastante de la balanza comercial del departamento de Arica, que no creían aventurado indicar "....al tenor de los resultados preinsertos, expresar [sus] temores para el futuro del comercio del puerto de ARICA y a su incidencia en las actividades industriales y comerciales del resto de Chile...", en tanto que:

“...Si en las condiciones actuales, de bastante amplia franquicia, el $90.5 \%$ del avance en el monto de las importaciones, entre 1955 y 1957 está configurando por el de artículos suntuarios; o innecesario o de normal producción en el resto del país, cabe preguntarse $<<_{i}$ A QUÉ EXTREMO LLEGARÁ AL ESTIMULARSE EL INCREMENTO MEDIANTE LAS DISPOSICIONES DE EXENCIÓN Y DE AUTORIZACIÓN CONTENIDAS EN EL ARTICULADO DE LA LEY QUE CREA LA JUNTA DE ADELANTO DE ARICA? > ..." (Cámara de Comercio de Santiago, 1958, pág. 23)

Si bien los temores expresados por la cámara comercial capitalina tuvieron reales fundamentos -sobre todo por los desajustes que se hicieron notar en la balanza comercial de exportaciones e importaciones hechas por medio del puerto y aduanas ariqueñas ${ }^{41}$ (ver Cuadro 2)-, estos en ningún caso invalidaron la evidente transformación que había comenzado a experimentar la ciudad de Arica mediante la aplicación de políticas especiales, medidas que se plasmaron, entre muchas otras cosas, en el exponencial aumento de la migración campo-ciudad-que se acentuó radicalmente desde la década del cuarenta en adelante-, en los cambios relevantes de la infraestructura de la ciudad, pero por sobre todo, en el evidente incentivo al comercio regional, el que dinamizó la circulación de mercancías a nivel fronterizo, con ello, la vida económica del puerto ariqueño volvió a tomar un nuevo impulso ${ }^{42}$ (Urzúa, 1972). La crítica de la Cámara de Comercio de Santiago, entidad representante de la elite mercantil santiaguina, a las nuevas políticas implementadas en la frontera norte (Puerto Libre y futura Junta de Adelanto), en efecto, no pudo sobreponerse a los argumentos políticos y económicos que esgrimió la elite regional ariqueña al poder central.

\section{Comentarios finales}

Las dinámicas económicas y sociales que experimentó Arica durante la primera mitad del siglo XX, desde la chilenización y posterior control territorial del Estado chileno sobre la frontera, hasta la aplicación de políticas especiales para facilitar la circulación de mercancías por la ciudad y la región transfronteriza (mediante el Puerto Libre), estuvieron cruzadas por ciertas contingencias que se plasmaron dentro de la vida económica y política del puerto y departamento de Arica como 
momentos de real ambivalencia. Las contradicciones más palpables, a este respecto, tuvieron relación con las aspiraciones de una elite local que quiso hacer de una ciudad portuaria atrasada, una plataforma moderna para la circulación mercantil, anhelo que, de tanto en tanto, chocaba con las condiciones materiales objetivas de una región cuyas posibilidades de definir su economía política a nivel local eran bastante limitadas. La centralidad geográfica del territorio -como espacio natural para el flujo comercial de la región centro-sur andina en el continente (Flores-Galindo, 1977)- y su evidente marginalidad política -expresión del lastre dejado por el centralismo chileno (Salazar, 2011)-, se expresaron cual continuidad de siglos pretéritos coloniales y republicanos decimonónicos (Rosenblitt, 2013), manteniendo durante la primera mitad del siglo XX parte de esas características estructurales de atraso económico en el territorio (Soto, 2019) (Dilla, 2016).

La ciudad y el puerto de Arica, a este respecto, tuvieron que ser pensados desde el discurso público de la elite dominante local, con una perspectiva que hiciera posible, a nivel táctico, el establecimiento de una política atractiva para los gobiernos nacionales de turno (como el gobierno agrario-laborista de Carlos Ibáñez, por ejemplo), así como también que tuviese sentido a los oídos de la elite capitalina (como la representada mediante la Cámara de Comercio de Santiago).

Cuando la sociedad civil ariqueña y sus representantes dirigenciales por fin pudieron agenciar una política de Estado para la ciudad y el departamento, las contradicciones se volvieron a plasmar a nivel de las discursividades y proyecciones políticas, sobre todo respecto del modo en que se ideó la instauración y finalidad del Puerto Libre. Mientras algunos propiciaron dicho proyecto como una política estratégica que confirmara la presencia del Estado en la frontera -desde una orientación proteccionista-, otros la defendieron como parte de una estrategia liberal que potenciaba mucho más el comercio transnacional en la región -en función de la circulación y acumulación del capital privado (como lo sostuvo el senador Alessandri)-. No obstante, tanto proteccionistas como liberales apoyaron la idea de instaurar un Puerto Libre en Arica, proceso que generó transformaciones considerables dentro de la vida económica regional, y que, con el tiempo, habilitó la formación de nuevas ideas y estrategias para potenciar el crecimiento y desarrollo de la frontera norte -por medio de la aplicación de una Junta de Adelanto, por ejemplo-, pese a los rechazos que esta idea generó en los círculos de poder de la capital, particularmente en la Cámara de Comercio de Santiago.

Es posible señalar entonces que, lejos de un proceso teleológico movido por la inquebrantable fuerza del progreso en la historia (Fontana y Aravena, 2011), la vida económica en la frontera norte durante la primera mitad del siglo XX estuvo cruzada por varios matices y contradicciones a nivel social, político y económico, realidades que debió enfrentar la elite regional ariqueña de manera no menos ambivalente -mediante discursos algunas veces proteccionistas, y en otras ocasiones, librecambistas-, conforme poder llevar a cabo el control efectivo del territorio, pero también, idear un futuro plausible al proyecto hegemónico chileno en la región fronteriza y el puerto de Arica. 


\section{Anexos}

Cuadro 1

\begin{tabular}{|c|c|}
\hline \multicolumn{2}{|c|}{$\begin{array}{c}\text { Minerales metálicos y no metálicos de productos metalúrgicos y de metales embarcados por el puerto de Arica } \\
\text { durante el año } 1921 \text { (con destino a cabotaje) }\end{array}$} \\
\hline Azufre & $\$ 1.375,738$ \\
\hline Sal & $\$ 268,34$ \\
\hline Barriles de estaño & $\$ 16,153$ \\
\hline Metales de cobre & $\$ 13,430$ \\
\hline Metales de plata & $\$ 3,640$ \\
\hline Estaño en barra & $\$ 21,540$ \\
\hline \multicolumn{2}{|c|}{$\begin{array}{c}\text { Minerales metálicos y no metálicos de productos metalúrgicos y de metales exportados por el puerto de Arica } \\
\text { durante el año } 1921 .\end{array}$} \\
\hline Metales de cobre & $\$ 288,200$ \\
\hline Borato calcinado & $\$ 37,515$ \\
\hline Azufre & $\$ 8,900$ \\
\hline
\end{tabular}

Fuente: (Varas, 1922, pág. 100).

Cuadro 2

Comercio Exterior por el Puerto de Arica

\begin{tabular}{ccccccc}
\hline & \multicolumn{5}{c}{ Miles de dólares } \\
\cline { 2 - 6 } Años & $\begin{array}{c}\text { Importaciones } \\
\text { (monto) }\end{array}$ & $\begin{array}{c}\text { Exportaciones } \\
\text { (monto) }\end{array}$ & Balance (saldos) & $\begin{array}{c}\text { Importaciones } \\
\%(1)\end{array}$ & $\begin{array}{c}\text { Exportaciones } \\
\%(2)\end{array}$ & $\begin{array}{c}\text { Relación } \\
\text { importaciones } \\
\text { exportaciones }\end{array}$ \\
\hline 1937 & 186 & 660 & 474 & 0,21 & 0,32 & 0,282 \\
1938 & 165 & 620 & -455 & 0,16 & 0,44 & 0,266 \\
1939 & 124 & 372 & 248 & 0,15 & 0,27 & 0,333 \\
1940 & 186 & 888 & -702 & 0,18 & 0,62 & 0,210 \\
1941 & 186 & 578 & 392 & 0,17 & 0,36 & 0,287 \\
1942 & 516 & 785 & 269 & 0,4 & 0,44 & 0,655 \\
1943 & 268 & 1156 & 888 & 0,2 & 0,64 & 0,232 \\
1944 & 413 & 1198 & 785 & 0,28 & 0,6 & 0,346 \\
1945 & 413 & 1033 & 620 & 0,26 & 0,49 & 0,399 \\
1946 & 537 & 681 & -144 & 0,27 & 0,3 & 0,790 \\
1947 & 680 & 639 & -41 & 0,25 & 0,23 & 1,062 \\
1948 & 1236 & 783 & -453 & 0,46 & 0,24 & 1,580 \\
1949 & 1071 & 618 & -453 & 0,36 & 0,2 & 1,738 \\
1950 & 1566 & 783 & -783 & 0,63 & 0,27 & 2,000 \\
1951 & 700 & 1156 & 456 & 0,21 & 0,29 & 0,606 \\
1952 & 1030 & 1112 & 82 & 0,28 & 0,24 & 0,922 \\
1953 & 865 & 1236 & 371 & 0,26 & 0,3 & 0,700 \\
1954 & 1556 & 559 & -997 & 0,45 & 0,14 & 2,789 \\
1955 & 8032 & 1163 & -6869 & 2,13 & 0,24 & 6,900 \\
1956 & 7915 & 1614 & -6301 & 2,24 & 0,29 & 4,900 \\
\hline 193 & & & & & \\
\end{tabular}

(1) Incluido el comercio por Chacalluta.

(2) Posiciones relativas a totales de importaciones y de exportaciones.

Fuente: Cámara de Comercio de Santiago, 1958. 
Cuadro 3

Población del departamento de Arica desde 1930 hasta 1960

\begin{tabular}{lcccc}
\hline & \multicolumn{4}{c}{ Censos } \\
\cline { 2 - 5 } & Año 1930 & Año 1940 & Año 1952 & Año 1960 \\
\hline Prov. de Tarapacá & 113.331 & 114.097 & 102.789 & 123.070 \\
Dpto. de Arica & 21.000 & 21.836 & 30.307 & 51.947 \\
Arica & 15.912 & 16.627 & 23.033 & 46.686 \\
Putre & 1.470 & 1.572 & 1.378 & 1.846 \\
Belén & 1.035 & 1.278 & 1.283 & 1.092 \\
Codpa & 1.046 & 986 & 1.314 & 1.207 \\
General Lagos & 1537 & 1373 & 3299 & 1116 \\
\hline
\end{tabular}

Fuente: Dirección General de Estadística, 1931. Dirección de Estadísticas y Censos, 1940. Servicio Nacional de Estadística y Censo, 1952. Dirección de Estadística y Censos, 1964.

\section{Referencias Citadas}

Basadre, J.

2005 La vida y la historia. Antología. Lima: El Comercio, S.A. Peruanos Imprescindibles.

Blanlot, T.

1910 "Las minas de Tacora i de Tignamar". En J. Arce, J.

Boccanegra, T. Blanlot, Ó. Cáceres, A. Pomareda, M.

Suárez, y V. Dagnino, Crónicas Ariqueñas (pp. 61-63).

Tacna: Librería e Imprenta La Joya Literaria.

Boldizzoni, F.

2013 La pobreza de Clío. Barcelona: Editorial Crítica.

Braudel, F.

2012 La dinámica del capitalismo. México: Fondo de Cultura Económica.

Cámara de Comercio de Santiago.

1958 El caso Arica. Santiago: Cámara de Comercio de Santiago.

Cipolla, C.

1991 Entre la historia y la economía. Introducción a la historia económica. Barcelona: Editorial Crítica.

Congreso Nacional de Chile.

3 de Marzo de 2020 Biblioteca del Congeso Nacional de Chile. Obtenido de Biblioteca del Congreso Nacional de Chile: https://www.leychile.cl/Navegar?idNorma=5367

Díaz, A., Galdames, L., y Ruz, R.

2010 Nación e Identidad en Los Andes. Indígenas de Arica y Estado chileno (1883-1929). Arica: Ediciones Universidad de Tarapacá.

Díaz, A., Salazar, P., y Soto, D.

2016 "Los obreros del volcán. Indígenas y proceso de transición laboral en las azufreras de Tacora y Taapaca”. Estudios Atacameños(52), 69-89.

Dilla, $\mathrm{H}$.

2016 "Chile y sus fronteras: notas para una agenda de investigación". Polis, 1-13.

Dirección de Estadísticas y Censos

1964 Población del país. Provincias. Departamentos. Comunas. Clasificada segun sexo (Censo de 1960). Santiago: Dirección de Estadísticas y Censos.

Dirección de Estadísticas y Censos

1940 Chile. XI Censo de Población (1940). Recopilación de cifras públicas por la Dirección de Estadísticas y Censos.
Santiago: Instituto Nacional de Estadísticas, Centro Latinoamericano de Demografía.

Dirección General de Estadística

1931 Resultados del X Censo de la Población. Efectuado el 27 de noviembre de 1930 y estadísticas comparativas con Censos anteriores. Santiago: Imprenta Universo.

Escuela de Transporte UCV

1972 "Arica como puerto natural de la región amazónica". Revista de Estudios del Pacífico, 53-62.

Flores-Galindo, A.

1977 Arequipa y el sur andino: ensayo de historia regional (siglos XVIII-XX). Lima: Editorial Horizonte.

Flores-Galindo, A.

1999 La tradición autoritaria: Violencia y democracia en el Perú. Lima: SUR, Casa de Estudios del Socialismo-APRODEH.

Fogel, R. W.

1966 "The New Economic History. I. Its Findings and Methods". The Economic History Review, 19(3), 942-656.

Fontana, J., \& Aravena, P.

2011). La historia que se piensa. Conferencias, clases y conversaciones en Chile. Concepción: Ediciones Escaparate.

Galdames, L.

2010 "El discurso del Estado a través de la creación del Puerto Libre de Arica. Aproximación semiológica". En A. Díaz, A. Díaz, y E. Pizarro, Arica siglo XX. Historia y Sociedad en el extremo norte de Chile (pp. 95-100). Arica: Universidad de Tarapacá.

González, S.

2008 La llave y el candado. El conflicto entre Perú y Chile por Tacna y Arica (1883-1929). Santiago: Ediciones Lom.

González, S.

2010 "El cantón Bolivia o Central durante el ciclo de expansión del nitrato". Estudios Atacameños(39), 85-100.

Hobsbawm, E.

1983 "De la historia social a la historia de la sociedad". En E. Hobsbawm, Marxismo e historia social (pp. 21-44). México: Universidad Autónoma de Puebla.

Hobsbawm, E.

2005 "El desafío de la razón. Manifiesto para la renovación de la historia". Polis, 4(11), 0. 
Keller, C.

1946 El Departamento de Arica. Santiago: Ediciones Zig-Zag.

Kocka, J.

1989 Historia Social. Concepto - Desarrollo - Problemas. Barcelona: Editorial Alfa.

Kocka, J.

2002 Historia social y conciencia histórica. Madrid: Marcial Pons, Ediciones de Historia, S. A.

Kula, W.

1970 "Una economía agraria sin acumulación. La Polonia de los siglos XVI-XVIII". Desarrollo Económico, 9(36), 483-507.

Larraín, J.

2001 Identidad chilena. Santiago: ediciones Lom.

Oficina Central de Estadística

1908 Memoria presentada al Supremo Gobierno por la Comisión Central del Censo. Santiago: Imprenta L Universo.

Palma, J. G.

1984 "Chile 1914-1935: de economía exportadora a sustitutiva de importaciones". Colección Estudios CIEPLAN(12), 62-88.

Pérez, N.

2014 Revolución Boliviana de 1952. Buenos Aires: editorial Ocean Sur.

Pinto, A.

1970 "Desarrollo económico y relaciones sociales". En A. Pinto, S. Aranda, A. Martínez, O. Caputo, R. Pizarro, E. Faletto, ... A. Dorfman, Chile, hoy (pp. 5-52). México: Siglo Veintiuno Editores.

Pizarro, C.

2016 Immanuel Wallerstein: Globalización de la economíamundo capitalista. Perspectiva de largo plazo. Santiago: Fondo de la Cultura Económica.

Pizarro, E., y Ríos, W.

2010 "Entre franquicias y beneficios: Una apuesta del gobierno para el desarrollo regional de Arica (1953)". En A. Díaz, A. Díaz, y E. Pizarro, Arica siglo XX. HIstoria y Sociedad en el extremo norte de Chile (pp. 79-93). Arica: Universidad de Tarapacá.

Romero, E.

2006 Historia económica del Perú. Lima: Universidad Alas Peruanas.

Rosenblitt, J.

2013 Centralidad geográfica, marginalidad política: La región de Tacna - Arica y su comercio, 1778-1841. Santiago: DIBAM, Centro de Investigaciones Diego Barros Arana.

Ruz, R., Galdames, L., y Díaz, A.

2015 Junta de Adelanto de Arica (1958-1976). Experiencia, documentos e historia regional. Arica: Universidad de Tarapacá.

Scott, J. C.

2000 Los dominados y el arte de la resistencia. México D.F.: Ediciones Era.

Servicio Nacional de Estadística y Censo.

1952 XII Censo General de Población y I de Vivienda. Levantando el 24 de Abril de 1952. Santiago: Servicio Nacional de Estadística y Censo.
Sewell Jr., W. H.

Junio de 2006 "Una teoría de estructura: dualidad, agencia y transformación”. Arxius(14), 145-176.

Sewell Jr., W. H.

2010 "A strange career: the historical study of economic life". History and Theory(49), 146-166.

Soto, D.

2014 "Tácticas de resistencia peruana durante la Chilenización de los altos de Arica. Discurso oculto, fiesta y manifestaciones populares (1900-1929)". En A. Díaz, R. Ruz, y L. Galdames, Tiempos violentos. Fragmentos de Historia Social en Arica (pp. 129-142). Arica: Ediciones Universidad de Tarapacá.

Soto, D.

2017 Habilitadores y jornaleros en la minería ariqueña a inicios del siglo XX: experiencias de actores mineros en los tiempos de la chilenización del extremo norte. Departamento de Arica, 1900-1930. Santiago: Tesis de Magister, Universidad de Santiago de Chile.

Soto, D.

2019 "Para una breve historia de la moderna frontera de Arica y Tacna: Coyunturas". En H. Dilla, \& C. Álvarez, La vuelta de todo eso (pp. 41-64). Santiago: Ril Editores, Universidad Arturo Prat, Instituto de Estudios Internacionales INTE.

Sztompka, P.

1993 Sociología del cambio social. Madrid: Alianza Editorial.

Tamayo, J.

1959 Geografía de América. México: Fondo de Cultura Económica.

Tamayo, J.

1982 Historia social e indigenismo en el altiplano. Lima: Ediciones Treintaitrés.

Urzúa, L.

1972 "Precursores del Puerto Libre. En U. de Chile", Enciclopedia de Arica. Ensayo de Información General del Departamento de Arica (pp. 36-38). Santiago: Editorial de Enciclopedias Regionales Ltda.

Varas, C.

1922 Tacna y Arica bajo la soberanía chilena. Santiago: Imprenta de "La Nación".

Vargas, G.

1903 El eterno debate Tacna y Arica. Refutación a unos artículos del ex-Intendente de Tacna señor M. F. Palacios. Lima: El Morro de Arica.

Vilar, P.

2013 Iniciación al vocabulario del análisis histórico. Barcelona: Editorial Crítica.

Vitale, L.

1992 "La cuestión agraria y minera y la renta del suelo". En L. Vitale, Introducción a una teoría de la Historia para América Latina (pp. 273-280). Buenos Aires: Editorial Planeta.

Vitale, L.

2009 Los principales períodos de la historia de América Latina. Santiago: Ediciones Lom.

Wormald, A.

1972 Frontera Norte. Santiago: Editorial ORBE. 


\section{Notas}

1 Archivo histórico perteneciente a la Universidad de Tarapacá, Arica-Chile.

2 Para el historiador francés Fernand Braudel, la distinción que se debe hacer entre la vida económica, por un lado, y la vida material, por el otro, dice relación con que “...Todo lo que queda fuera del mercado no tiene sino un valor de uso, mientras que todo lo que traspasa su estrecha puerta adquiere un valor de intercambio. Según se encuentre a uno o a otro lado del mercado elemental, el individuo, el "agente", se encuentra o no incluido dentro del intercambio, dentro de lo que he llamado vida económica, para contraponerla a la vida material, y para distinguirlo también [...] del capitalismo..." (2012, pág. 24).

3 Como lo propusieron en su momento las y los defensores de la cliometría y/o la nueva historia económica (Fogel, 1966). Para una crítica de estas corrientes en historiografía, ver a Francesco Boldizzoni (2013).

4 Escenario muy similar al que se gestó en regiones de América Latina y el mundo, donde la prevalencia de las viejas estructuras gamonales o aristocráticas subsumían los procesos de modernización o surgimiento de nuevas clases sociales modernas (Vitale, 1992) (Kula, 1970). A este respecto, Alberto Flores Galindo caracterizó al sur peruano de finales del siglo XIX y comienzos del XX -contemplando a la entonces provincia de Tacna y Arica-como un espacio donde, a partir de dicho transe histórico “...queda constituido el gran dominio, la gran propiedad terrateniente, el latifundio en el sur..." (1977, pág. 105). No deja de llamar la atención que tal caracterización tenga semejanzas al proceso de acumulación surgido en el Norte Grande de Chile, al alero de ciclo del salitre, coyuntura económica que, pese a la acumulación de capital articulado desde las salitreras, poca incidencia tuvo en la modernización de los modos de producción y explotación del así llamado oro blanco (González, 2010) (Palma, 1984). El surgimiento de burguesías esquivas a los procesos de modernización -y de cambio social-, y sostenidas mediante la acumulación de la renta de la tierra (de la propiedad agrícola en el sur peruano, y de la explotación minera en el norte chileno), pueden ser elementos característicos en uno y otro lado de la frontera chileno-peruana a inicios del siglo XX, lo que da cuenta de continuidades y similitudes estructurales dentro de un espacio fronterizo separado por la contingencia diplomática (Soto, 2017).

5 El informe del Censo de 1907 -efectuado por autoridades chilenas-, describía del siguiente modo el territorio departamental: “...Las corrientes de agua que riegan la provincia son de escaso caudal i ninguna merece el nombre de rio $\left[\ldots .\right.$. La temperatura al nivel del mar no pasa de $19^{\circ}$ centígrados. Las lluvias mui escasas en la alta cordillera, faltan del todo hacia la costa. Algunos valles profundos i poco ventilados están expuestos a las tercianas o fiebres intermitentes. La vegetación natural, a causa de la falta de humedad, es casi nula, principalmente en las pampas del interior i en las cercanías del mar; así, el aspecto general de la provincia es el de un desolado desierto. Los valles, en los reducidos espacios a que alcanzan las aguas de regadío, presentan buenas condiciones para el cultivo. Allí se ven al lado de los vegetales propios de la zona tórrida, los que prosperan en los países templados. La alfalfa, la vid, las legumbres, el olivo i los árboles frutales de la Europa meridional, prosperan junto al algodonero i al banano. Pero los productos agrícolas de la provincia no bastan ni con mucho al consumo de su limitada población. Aunque existen en la provincia variadas riquezas minerales, la única que se explota en cierta escala es el azufre, en las solfaturas de Tacora. El comercio de tránsito con Bolivia, que constituye el principal recurso de los habitantes, se encuentra mui decaído después de la apertura del Ferrocarril de Mollendo al lago Titicaca; pero renacerá en breve, cuando esté terminada la línea que ha de unir al puerto de Arica con el Alto de La Paz..." (Oficina Central de Estadística, 1908, pág. 4).

6 Acordado en el Tratado de 1904 entre Chile y Bolivia (González, 2008).

7 “...Con motivo de la construcción del ferrocarril de Arica a La Paz, el puerto adquirió un gran desenvolvimiento comercial y se redoblaron los servicios aduaneros, por lo cual el Supremo Gobierno creó la sección boliviana de la Aduana, a fin de reforzar el personal aduanero y hacer un servicio eficiente y que inspirara garantías para el alto comercio de tránsito con Bolivia por esa importante vía internacional..." (Varas, 1922, pág. 97).

8 Movimientos de carga mercante en el puerto de Arica, como el que se expresa a continuación, son constantes entre 1929 y 1930, respectivamente: “...Vapor Holandés Barneveld procedente de Hamburgo consignado a G. P. Finlayson. Carga para el puerto, 441 bultos. Carga para el Perú, 50 bultos. Carga para Bolivia, 2174 bultos [ilegible] Motor nacional "Diana", procedente de Iquique consignado a J. A. Quirós. Sin carga. Salidos día 3. Vapor Holandes "Barneveld" con destino a Corral despachado por G. P. Finlauson. Motor nacional "Diana", con destino a Iquique despachado por J. A. Quirós.” En: Archivo Histórico Vicente Dagnino [de ahora en adelante: AHVD], Fondo de Prensa, Diario El Pacífico, miércoles 4 de diciembre de 1929.

9 Es el caso de Alfonso Quiroz, por ejemplo, quien, siendo habilitador minero, también ejercía como comerciante, enviando mercancías hacia Bolivia a través de diversas agencias comerciales marítimas: "MOVIMIENTO DEL PUERTO DE ARICA. Naves. Vapor nacional "Apolo", procedente de Valparaíso consignado a J A. Quiroz. Carga para el puerto, 166 bultos. Carga en tránsito a Bolivia, 2.400 bultos..." En: AHVD, Fondo de prensa, El Pacífico, 07 de enero de 1930.

10 El en diario El Pacífico, una columna editorial titulada "La urbanización de Arica”, planteaba lo siguiente: “...Con motivo de la llegada a este puerto de los técnicos especialistas en urbanización de ciudades, los señores Brunner y Muñoz, que han venido por encargo especial de S. E. el Presidente de la República, a estudiar los problemas de una transformación total y definitiva de Arica, este tema se ha puesto de latente actualidad, tanto más cuando se están desarrollando las gestiones para que por intermedio de la Caja de Retiro y de Previsión Social de los Ferrocarriles, los empleados y obreros de nuestra Empresa internacional puedan adquirir terrenos y edificar un minimun de sesenta casas, número suficiente por si sólo para formar todo un 
barrio. [...] Es un hecho que no admite discusión, que tarde o temprano tendrá que conseguirse la irrigación del valle de Azapa, ya que de este solo problema depende todo el provenir de Arica, Cuanta obra de progreso se emprenda en este puerto, no podrá tener la influencia decisiva para su adelanto y bienestar como lo tendrá el regar las tierras que le darán vida propia, estable y verdadera. [...] No miremos con indiferencia estos proyectos, hace treinta años la avenida Libertad de Viña del Mar eran unos arenados estériles y desolados, el metro valía \$3.- y hoy están a \$200. Arica no puede extenderse al oriente, esa parte baja está puesta a ser barrida por el mar en la misma forma como, lo ha sido en dos o tres ocasiones. ¡El porvenir de Arica está en Azapa y en su camino! ..." AHVD, Fondo de prensa, diario El Pacífico, miércoles 4 de diciembre de 1929.

11 AHVD, Fondo de prensa, diario El Pacífico, lunes 13 de enero de 1930.

12 Continuaba diciendo que “...Para fundarlos debe simplificarse el problema inicial, reduciéndolo simplemente a la voluntad de sindicarse y a la constitución misma de sindicato. Será esta la mejor forma de llegar a resultados prácticos, sin complicar la organización que siempre ofrece algunas dificultades. Una vez formados los sindicatos, siempre habrá tiempo para considerar cualquier otro problema. Esta idea que le sujiero le ruego considerarla como un aporte de valor práctico a la rápida constitución de los sindicatos; que son la verdadera célula de la organización obrera..." AHVD, Fondo de prensa, diario El Pacífico, domingo 12 de enero de 1930.

13 Conforme lo aquello, seguía sosteniendo la línea editorial que todos esos elementos “....Hacían de Arica el ser Puerto Libre, el indicado para servir de almacén proveedor de mercaderías de importación [...] en los diversos mercados de América del Sur..." (Pizarro \& Ríos, 2010, pág. 82).
5 En específico, la implementación de un programa industrial para el puerto de Arica buscaba abordar los siguientes puntos: “...1) Organizar la pesca de costa y alta mar en una forma científica y técnica de manera que ella sea comercialmente explotada y produzca no solamente para el abastecimiento del pescado fresco para el consumo de la población, sino también para el abastecimiento para las fábricas de industrialización total del pescado y exportación de algunos productos, única forma en que será factible y comercial la industria pesquera. 2) Organizar practica y comercialmente la venta del pescado fresco, interviniendo directamente en ella ante el pescador a fin de hacer desaparecer en la mejor forma posible los intermediarios y conseguir que el pescador obtenga la legitima y justa retribución que le pertenece y que al mismo tiempo el público consumidor obtenga en todo momento toda clase de pescado abundante y barato. 3) Organizar la industrialización total de los peces, en forma que quede en condición de recibir todo el pescado, cualquiera sea la época y la cantidad que se traiga, a fin de que los gremios de pescadores, no sigan sujetos a la situación actual en el cual se ven obligados a sacrificar los precios porque no se les recibe el pescado cuando hay abundancia. 4) Organizar el consumo del pescado fresco de manera que él sea el alimento cotidiano del pueblo, acostumbrándole a consumir toda clase de pescados mediante una buena y variada preparación culinaria. 5) Organizar la explotación de pescado fresco y congelado a Bolivia y EE.UU. que serán grandes y seguros consumidores de nuestro pescado, dando auge y progreso a nuestra industria pesquera...". Ver en: AHVD, Fondo de prensa, La Gaceta, 12 de julio de 1940.

16 A este respecto, una nota escrita en La Gaceta, señalaba que “...una nueva línea de barcos mercantes permitiría también la descongestión del problema marítimo de nuestras costas, cuya gravedad la sienten principalmente estos pueblos del norte, que tienen una tardía vinculación con el resto del país..." AHVD, Fondo de prensa, diario La Gaceta, 08 de febrero de 1940.

17 De hecho, una nota publicada en El Ferrocarril daba cuenta de la desigual inversión pública establecida en la provincia de Tarapacá, siendo los departamentos con mayor inversión los de Pisagua e Iquique (con \$ 54.702 el primero, y 245.827 el segundo), quedando el de Arica relegado (con escasos $\$ 24.799$, en contraste al resto de cifras mencionadas), para el año 1936. Ver en: Pizarro y Ríos (2010, pág. 83).

18 En 1940, por ejemplo, la Junta Central del Partido Radical, mediante sus representantes en Arica, daban cuenta de que “...en reunión de gran importancia [se] acordó pedir al Ministro de Relaciones Exteriores, señor Cristobal Saenz, la designación de una comisión especial que estudie el proyecto que declara a Arica puerto libre. Considerada la importancia que tiene esta medida, es indudable que se le dará todo el interés que esto merece...” AHVD, Fondo de prensa, diario La Gaceta, 07 de marzo de 1940.

19 Así lo expresaba la Junta Central del Partido Radical, “... autoridad máxima del Radicalismo Chileno, [la cual] en reunión de gran importancia acordó pedir al Ministro de Relaciones Exteriores, señor Cristóbal Saenz, la designación de una comisión especial que estudie el proyecto que declara a Arica puerto libre. Considerada la importancia que tiene esta medida, es indudable que se le dará todo el interés que esto merece...". Ver en: AHVD, Fondo de prensa, La Gaceta, 07 de marzo de 1940.

20 El diputado del Partido Liberal, Humberto Arellano Figueroa, aseguraba en 1940 que el propio presidente Pedro Aguirre Cerda también apoyaba la idea de un puerto libre para Arica. Prontamente estos supuestos serían desmentidos, a través de las líneas del propio diario local ligado al radicalismo, La Gaceta, donde uno de sus periodistas afirmaba que: “... Desde este histórico territorio, con el miraje constante en ese baluarte de grito que es la herencia de los bravos, e invocando a las manos de los valientes que allí rindieron sus vidas puedo decirle al H. Sr. Diputado Arellano que Arica no será declarado puerto libre..." Ver en: AHVD, Fondo de prensa, La Gaceta, 11 de septiembre de 1940.

21 AHVD, Fondo de prensa, La Gaceta, 12 de julio de 1940. 22 Así se dejaba ver la idea del puerto libre entre el gremio de pescadores de Arica, por ejemplo: “...Desde hace tiempo el gremio de Pescadores viene preocupado de mejorar las posibilidades de mercados permanentes para el producto de su trabajo. Y cabe manifestar, en forma explícita, esos deseos han encontrado la mejor atención en el actual Director de Fomento don Vital Misiego, a quien secunda en forma concluyente en este puerto, el señor Héctor Parodi. Hasta el momento para las expectativas del gremio de 
pescadores son magníficas bajo todo punto de vista. [...] Conseguido esto [el Puerto Libre], su triunfo es definitivo, ya que no solo se vislumbra la libre internación a Bolivia de productos de pesca, donde el mercado es inmenso, sino singularmente que el Instituto de Fomento que dirige con toda inteligencia el señor Misiego, instalará en Iquique una gran Fábrica de conservas y para darle abasto a ese bien montado establecimiento, no basta ni puede bastar el gremio de Iquique; tendrá que apelarse a pescadores desde Tocopilla hasta Arica. Todo esto indica, que las expectativas para el Gremio de Pecadores, son fáciles de vaticinar y solo cabe desear el más rápido cumplimiento que todo eso viene directamente a beneficiar a nuestro puerto a su comercio y a todos sus habitantes..." Ver en: AHVD, Fondo de prensa, La Gaceta, 10 de agosto de 1940.

23 Es interesante ver que las promesas que giraron en torno al proyecto de puerto libre, que supuestamente potenciaría la modernización del muelle ariqueño, estaba sujeta moralmente a la condición de que los pescadores abandonaran sus antiguos modos de pesca tradicionales - los cuales, sin lugar a dudas, eran bastante peligrosos-. La nota citada anteriormente menciona a este respecto que “...El Instituto de Fomento tiene la mejor voluntad para ayudarlos y habilitarlos con cuanto necesiten[al gremio de pescadores], siempre por cierto que compruebe ese gremio, laborioso como eficiente, todo el empeño que debe poner par su labor, tanto con una dedicación permanente, como así mismo cuidar de abolir la antigua costumbre como la de pescar con dinamita...”. Ver en: AHVD, Fondo de prensa, La Gaceta, 10 de agosto de 1940.

24 AHVD, Fondo de prensa, La Gaceta, 16 de septiembre de 1940. La columna además hace mención de toda la problemática asociada al ingreso de población extranjera que traería consigo la implantación del puerto libre, aspecto que, según el columnista, sería difícil de manejar tanto para Chile así como para las autoridades locales: “...Se les ha dicho [a las y los ariqueños] que aun la explotación misma del F. C. de Arica a La Paz intensificaría su tráfico de movilización de mercadería y productos de todo género; que la aduana se haría estrecha para contener quizás los millones y millones de toneladas de carga en tránsito y que, todo esto, forzosamente debería entonar el ambiente económico del puerto y que sus habitantes gozarían de las más amplias franquicias que un Gobierno democrático puede legislar a favor de las masas. Esas masas de pobladores en este puerto (seamos francos), no son todos chilenos. Y si Chile y su Gobierno democrático amparan con sus leyes y sus códigos los derecho y deberes del pueblo, ya sea este formado por el conglomerado d chilenos criollos o por extranjeros radicados en sus territorios, en cambio, no sería lo mismo la aplicación de ciertas disposiciones en este territorio septentrional del país, pues la invasión de elementos extranjeros revestidos de industriales, fabricantes, comerciantes de diversas categorías, etc., acarrearía para el gobierno otro problema fuera del que tendría que soportar con la implantación de la ley que creara el puerto libre..."

25 Una polémica interesante fue la que se diera en Arica al alero de lo establecido por el diputado Humberto Arellano Figueroa, quien aseguraba que el presidente Pedro Aguirre Cerda, mientras aún era candidato presidencial, había prometido la instauración del puerto libre para la ciudad en cuestión. A este respecto, los periódicos locales matizaron estos dichos y, según sus propias líneas editoriales, acusaban lo inoportuno de establecer dicho debate en aquel momento político. El periódico La Gaceta manifestaba que: “....Este diario preocupado constantemente de todos los problemas regionales de este departamento y manteniendo abiertas sus columnas a todas las opiniones, sin banderías; pero guiando su norte político a servir la causa de redención nacional en que el histórico Partido Radical está empeñado, fue el primero en apoyar esta declaración oficial: de que Arica no será declarado Puerto Libre. Ahora, es el propio Presidente de Chile, Excmo. señor Pedro Aguirre Cerda, quien se lo manifiesta, cara a cara, al mismo autor de uno de los proyectos, el H. diputado por la agrupación política de Tarapacá, don Humberto Arellano Figueroa. [...] S. E. ha declarado; sin ambages, <que no era partidario de declarar Arica Puerto libre y que jamás lo había prometido>. [...] En diversas localidades [los periódicos] han publicado y siguen haciéndolo en el sentido de recordad, ahora, no solo a S. E. sino a diversos hombres públicos las $<$ promesas sobre tal o cual problema a discutirse en el Congreso Nacional, o bien que se inicien los debates parlamentarios de proyectos de leyes que van encaminados al engrandecimiento de la nación algunos, y otros, -como el del Puerto Libre de Arica- que sirve en la hora actual como de plataforma política para la propaganda de pre-candidatos. Por este terreno, llegaríamos a la fatal conclusión de tener que culpar al jefe del Estado y a los hombres públicos de faltar a sus palabras empeñadas en miles de "promesas", que son deseos de una hipotética verificación sujeta vaivenes y a altas y bajas temperaturas barométricas en el ambiente político. Suponiendo el caso de que se quiera por parte del H. diputado señor Arellano tildar al S. E. de faltar a su palabra por haber prometido "hacer de Arica un Puerto Libre, ya que con imperio así lo plasma la noticia telegráfica del matutino local, nos encontraríamos con un recurso positivo que salvaría legalmente la responsabilidad que lleva ante el procedimiento gobernativo del Jefe de Estado el cual se traduciría simplemente en que el S. E. ha optado por no reconocer una promesa incumplida. Y, como esto, el H, señor Arellano si en verdad anhela el bienestar para este territorio no debe insistir majaderamente en la [futilidad] de su proyecto inoportuno...". Ver en: AHVD, Fondo de prensa, La Gaceta, 23 de septiembre de 1940.

26 AHVD, Fondo de prensa, La Gaceta, 27 de septiembre de 1952.

27 El gobernador de Arica, Carlos Vildoso, propondría que “...una fórmula de solución [al problema del ferrocarril] sería obtener la autonomía del F.C. de Arica a La Paz, para que este dependiera directamente del Ministerio de Obras Públicas y Relaciones Exteriores, dada su condición de ferrovía internacional..."Ver en: AHVD, Fondo de prensa, La Gaceta, 27 de septiembre de 1952.

28 Ese tipo de argumentos, que eran usuales durante y después de la Chilenización de Arica, serían usados incluso a mediados del siglo XX, como lo enfatiza la siguiente reseña de prensa durante la visita de Carlos Ibáñez a Arica, en la cual, además, se desprende la constante comparación entre Arica y el trato que otras naciones vecinas dan a sus urbes limítrofes: “...Nuestra ciudad amanecerá mañana vestida de gala. La visita del Excmo. presidente de Chile, don 
Carlos Ibáñez del Campo, quien ha deseado imponerse en el mismo terreno de cuanto le sea posible solucionar dentro del muy precario estado de la Caja de los caudales públicos de la nación. Arica, por su situación dentro del mapa de la nación, se encuentra en singulares circunstancias, ya que se observa por naciones hermanas y vecinas de como se le atiende por el Gobierno, de la Patria y por su parte, los que en ella habitamos, no somos flojos en comparar cuanta preferente ayuda prestan sus respectivos gobiernos a nuestras limítrofes vecinas. Por esto, es un verdadero respiro de satisfacción, la bien honrosa como deferente visita que nos hace el timonel de la nación en momentos que recientemente asume el mando de su país...". Ver en: AHVD, Fondo de prensa, La Gaceta, 08 de abril de 1953. AHVD, Fondo de prensa, La Gaceta, 08 de abril de 1953 En esta última línea, y sobre el camino de Arica a Iquique, la nota editorial de La Gaceta manifestaba que: “...[de] una vez por todas [el presidente] ordene a la Superioridad de las obras viales, que el camino que une Iquique con Arica, sea definitivamente construido, salvando por cierto todo escollo que pueda impedir en épocas como las señaladas, su correcta circulación..." Por otro lado, respecto de las obras de sondajes, “....esas obras no rinden los beneficios que de ellas se esperan, ya sea por falta de maquinarias apropiadas, técnicos en su explotación o demasiada burocracia con sueldos elevados que privan de un mayor ejercicio de parte de la mano de obra trabajadora..." De este modo, en el balance global hecho desde La Gaceta, que abordaba diferentes temáticas que iban desde la escolaridad, el alumbrado público, las fuerzas de orden y la gestión política de los municipios, etc., se hacía notar que las problemáticas que existían en Arica eran del tipo globales (estructurales). Ver en: AHVD, Fondo de prensa, La Gaceta, 08 de abril de 1953.

31 Por ejemplo, respecto del funcionamiento de la municipalidad y de los procesos eleccionarios a nivel local, el director de La Gaceta señalaba que: “...Conversando con personas que en realidad se interesan por el progreso de este hoy Departamento, se han expresado decididamente porque se debiera pedir a S. E. la designación directa del Jefe Comunal a fin de apartarla de toda política que en la mayor de las veces es un negativo directo para el progreso de pueblos o ciudades..." Ver en: AHVD, Fondo de prensa, La Gaceta, 08 de abril de 1953. AHVD, Fondo de prensa, El Pacífico, 26 de enero de 1932. AHVD, Fondo de prensa, La Gaceta, 10 de abril de 1953. El gobernador de Arica, Busto Quezada, planteaba algo parecido tras recibir al presidente Ibáñez, manteniendo la siempre presente retorica patriotera: “...Arica es el baluarte de nuestra nacionalidad. No es un rincón de la patria como alguien escribió, sino que es la puerta de Chile. Estoy en un recinto militar, y como tal puedo hablarles con esa lealtad del soldado. En este Santuario de la Patria que es Arica, hay algo que vale mucho más que sus riquezas industriales y minera, y eso es esa lealtad y respeto para el Primer Mandatario de la Nación. Sus habitantes y el propio pueblo que lo llevó al sillón presidencial el 4 de septiembre está con Ud. y a vuestro lado mi General. Arica desea caminos y más caminos, pues sin ellos no hay progreso Yo le pido mi General abordar todos los problemas. Estos son muchos como vivienda, falta de locales escolares todo lo cual se consulta en el Plan Arica cuyo memorial entregaré en sus manos esta noche. Por su clima está llamado a ser un verdadero centro de Turismo para los vecinos de Tacna, Arequipa como igualmente de Bolivia. Antes de emprender yo viaje a Arica en diciembre último Ud. mi General me dijo en su casa que deseaba convertir a Arica al igual que lo hizo con La Serena, González Videla, y confió y estoy seguro que Ud. lo cumplirá porque es hombre de realizaciones..." Ver en: AHVD, Fondo de prensa, La Gaceta, 10 de abril de 1953.

35 AHVD, Fondo de prensa, La Gaceta, 10 de abril de 1953

36 AHVD, Fondo de prensa, La Gaceta, 10 de abril de 1953 [la cursiva procede del presente artículo].

37 De hecho, las consideraciones del senador Alessandri eran bastante altisonantes respecto del futuro de Arica bajo las premisas del libre mercado. Señalaba con bastante énfasis que: “....La posesión geográfica de Arica, vuelvo a repetirlo, es privilegiada, ya que se encuentra en la conjunción de tres naciones: Chile, Perú y Bolivia, y es actualmente y lo será mañana en mayor grado, el puerto de atracción de inmensas zonas de imponderable riqueza. A este respecto puede compararse nuestro puerto con los europeos de Amberes, Rotterdam y Trieste. Al ser declarada Arica zona libre para el comercio internacional, eliminadas las barreras aduaneras y los controles de cambio, se transformaría en un centro marítimo y comercial de primera categoría, y pasaría a ser una puerta abierta hacia el Pacífico de las llanuras, mesetas y selvas del interior del continente, fabulosamente ricas en minerales, productos agropecuarios y maderas. Esta experiencia no significará ningún sacrificio para la fiscal, ya que las entradas aduaneras de Arica son muy modestas, casi insignificantes. Estoy convencido, además, que los felices resultados que tendrían la implantación de la libertad de cambios en una porción de nuestro territorio, inducirían a nuestros gobernantes a implantarla en todo el país..." Ver en: AHVD, Fondo de prensa, La Gaceta, 10 de abril de 1953. 38 AHVD, Fondo de prensa, La Gaceta, 10 de abril de 1953. 39 Señalando específicamente el Decreto Supremo que: “.... Por los puertos de Chacalluta y Arica se permite a toda nave, aeronave u otro vehículo, entrar y salir libremente sin pagar los derechos e impuestos que a continuación se indican, franquicia que se extenderá a las mercaderías que trasporten dichos vehículos y que se internen para el uso, consumo o la libre circulación dentro de la región liberada a que se refiere el inciso primero del articulo siguiente: a) Los establecidos en el Arancel Aduanero y adicionales; b) Los impuestos de embarque y desembarque fijados por la ley N.o 3.852, y sus modificaciones; c) Los impuestos advalorem establecidos en el decreto de Hacienda N.o 2.772, de 18 de Agosto de 1943, y en sus modificaciones; d) La contribución de Faros y Balizas y los derechos de Hospital y de Cabotaje; y e) Los derechos consulares que gravan los conocimientos y facturas..." (Congreso Nacional de Chile, 2020).

40 En palabras de la Cámara de Comercio de Santiago, había que “...evitar que se [consumiera] un atentado contra la economía nacional...” (1958, pág. 2), es decir, que la política especial para Arica no terminara perjudicando al comercio y a la producción dentro del país.

41 Agregando además que, buena parte de los productos importados eran suntuarios que también se producían en 
otras ciudades de Chile. De este modo, el discurso de la Cámara de Comercio de Santiago, si bien abogaban por el resguardo de sus intereses, parecía también denunciar las consecuencias de un comercio exterior que no regulaba ni protegía la producción local-nacional (Cámara de Comercio de Santiago, 1958).

42 En palabras del Luis Urzúa: “...El interés de numerosos grupos por radicarse aquí [en Arica], desde luego, dio origen a una concentración humana densa y dinámica. La ciudad se extendió en sorprendente hipertrofia de calles, pasajes y avenidas. La Oficina de Bienes Nacionales había recibido, el año 1953, solamente 305 solicitudes de sitios. Estas peticiones crecieron año tras año y entre 1954 y 1957 llegaron a un total de 3.807 , lo que representa un promedio de 952 solicitudes anuales..." (1972, pág. 43). 